\title{
Unpackaging Demand for Water Service Quality: Evidence from Conjoint Surveys in Sri Lanka
}

\author{
Jui-Chen Yang, Subhrendu K. Pattanayak, F. Reed Jonson, Carol Mansfield, \\ Caroline van den Berg, and Kelly Jones^
}

\begin{abstract}
In the early 2000s, the Government of Sri Lanka considered engaging private sector operators to manage water and sewerage services in two separate service areas: one in the town of Negombo (north of Colombo), and one stretching along the coastal strip (south from Colombo) from the towns of Kalutara to Galle. Since then, the government has abandoned the idea of setting up a public-private partnership in these two areas. This paper is part of a series of investigations to determine how these pilot private sector transactions (forming part of the overall water sector reform strategy) could be designed in such a manner that they would benefit the poor.

This paper describes the results of a conjoint survey evaluating the factors that drive customer demand for alternative water supply and sanitation services in Sri Lanka. We demonstrate how conjoint surveys can be used to un-package household demand for attributes of urban services and improve the design of infrastructure policies. We present conjoint surveys as a tool for field experiments and source of valuable empirical data. In our study of three coastal towns in southwestern Sri Lanka the conjoint survey allows us to compare household preferences for four water supply attributes - price, quantity, safety, and reliability. Sub-populations of poor and non-poor households are examined to determine if demand is heterogeneous. Our case study suggests that households care about service quality (not just price). In general, we find that households have diverse preferences in terms of quantity, safety, and service options, but not with regard to hours of supply. In particular we find that the poor have lower ability to tradeoff income for services, a finding that has significant equity implications in terms of allocating scarce public services and achieving universal water access.
\end{abstract}

World Bank Policy Research Working Paper 3817, January 2006

The Policy Research Working Paper Series disseminates the findings of work in progress to encourage the exchange of ideas about development issues. An objective of the series is to get the findings out quickly, even if the presentations are less than fully polished. The papers carry the names of the authors and should be cited accordingly. The findings, interpretations, and conclusions expressed in this paper are entirely those of the authors. They do not necessarily represent the view of the World Bank, its Executive Directors, or the countries they represent. Policy Research Working Papers are available online at http:/lecon.worldbank.org.

- Subhrendu K. Pattanayak is a Fellow, RTI International (subrendu@rti.org). Jui-Chen Yang and Kelly Jones are Associate Economists at RTI International. Reed Johnson is a Senior Fellow at RTI International. Caroline van den Berg is a Senior Economist in the Energy and Water Department of the World Bank. Carol Mansfield is a Senior Economist at RTI International. 


\section{Introduction}

Large numbers of households in many less developed countries (LDCs) continue to cope without good quality water and sanitation services (WSS). As is true for many other services, the poor are more likely than the non-poor to receive poor quality WSS services. Bosch et al. (2000) find that fewer poor households are connected to water networks and many poor households have access to lower-quality services than non-poor households. Poor households bear a higher burden, as measured through time, health and energy, than non-poor households. WSS service provision in Sri Lanka is subject to similar problems. As discussed below and in more detail in Pattanayak et al. (2005a), contrasted with the rich, the poor consume less water per capita, and they are less likely to use safe water sources or engage in preventative measures such as treating their water or purchasing storage tanks. As a result, the poor are more likely to suffer from water-related diseases.

In the early 2000s, Sri Lanka, like many other LDCs at the time, was considering the possibility of inviting the private sector to operate WSS services, specifically around three coastal towns: Negombo, Kalutara and Galle. There were during the preparation process for these public-private partnerships concerns that such arrangements in WSS services may exacerbate the existing inequalities in WSS between poor and non-poor households. In 2004, the government abandoned its plan for setting up such a public-private partnership.

In this paper, we describe the results of a stated preference conjoint survey administered in Sri Lanka to assess demand for WSS services not just with respect to price, but with respect to important WSS service features. Our analysis contrasts the responses of the poor ${ }^{1}$ and non-poor, providing valuable information for those who seek to improve WSS services in a cost effective manner. Without a detailed understanding of why and how people desire WSS services, it difficult to increase coverage of these services and achieve the resulting social, health and economic benefits as it will not be possible to adapt policies to consumer preferences. Microeconomic studies can be used to evaluate factors that drive an individual's demand for WSS services. Estache et al. (2002) argue persuasively that inputs from microeconomic

\footnotetext{
1 Poor households are defined as those households in the bottom two deciles, or the bottom quintile, of the income distribution; poor households spend less than or equal to SLR 3,356 per capita per month.
} 
studies are critical to institutional reform of the WSS sector and for the privatization process, particularly in the development of policy instruments to address accessibility and affordability for poor households.

Past microeconomic studies have focused almost exclusively on costs as being the primary concern of water and sanitation customers and the major constraint to demand. However, a review of other service industries (Eto et al., 2001) and intuition suggest that consumers place value on multiple service attributes, not just costs. Recently, Pattanayak et al. (2001, 2004) and Hensher et al. (2004) have used more flexible approaches such as conjoint methods to show that customers do value multiple attributes of piped water supply.

Stated preference approaches allow the researcher to evaluate new goods, services or policies for which no observational data exists. Conjoint analysis represents a type of field experiment in which the researcher manipulates the WSS service features offered to respondents to create options that may not currently exist (Harrison and List 2004). Conjoint analysis offers a compromise between a controlled experiment in which WSS services are randomly varied across the population and consumer data, which has too little variation for analysis. For example, if everybody in the sample pays exactly the same price, it will be impossible to trace out a demand curve using consumer data.

Information from conjoint analysis can be used in service delivery programs to design appropriate service levels and tariffs, balance costs with service attributes, and increase consumer demand. By estimating the relative value placed on different service attributes, along with costs, customer preferences for different attributes can be ranked. Conjoint analysis can also be used to estimate willingness to pay for the sample as a whole and across sub-populations.

We begin in Section 2 with a description of conjoint surveys, showing how they can serve as a tool for field experiments and source of valuable empirical data. We emphasize the design and logistical challenges associated with applying the conjoint method in the field. In Section 3 we use data from our recent conjoint survey conducted in Sri Lanka to evaluate WSS preferences for poor and non-poor households. Through the conjoint survey data, we can determine what service attributes affect WSS demand and whether these attributes vary across poor and non-poor households. We find that households care about service quality (not just price) and the households have diverse preferences in terms of 
quantity, safety, and service options, but not hours of supply. However, the poor have lower ability to tradeoff income for services (i.e., higher marginal utility of income). Section 4 presents the policy implications of our findings - findings that have serious equity implications for allocating scarce public services and achieving universal water access. We conclude with some suggestions for future uses of conjoint analysis in the design and evaluation of water and sanitation programs.

\section{Conjoint Surveys as Field Experiments}

Conjoint analysis has long been applied in market research to assist in the design of new products (Cattin et al., 1982). Many environmental economists have turned to conjoint analysis methods because of validity concerns identified in some contingent valuation studies (Adamowicz et al., 1999). Similarly, health economists also have become interested in the use of conjoint analysis as an alternative to contingent valuation (Ryan et al., 2001). The conjoint methodology is based on rigorous utility-theoretic principles (Louviere, Hensher, and Swait, 2000). Using conjoint analysis, goods are described by a series of attributes with varying levels. Using an experimental design, the attribute levels are combined to produce a collection different goods, or WSS alternatives in the case of our study. In the survey, respondents are presented with two or more options for WSS service levels and associated prices. Respondents select the option they prefer. Each respondent answers a set of choice questions (the optimal number, also determined by an experimental design, depends on the number of attributes and levels) to provide the level of variation needed for estimating the marginal utilities of each attribute. By asking respondents to make choices about different attribute combinations, researchers can determine the importance of different attributes and levels, the probability that individuals would select, for example, a particular WSS alternative compared to their current WSS situation, and to estimate willingness to pay for changes in attribute levels or for one WSS alternative versus another (Hensher et al., 2004; Mercer and Snook, 2004).

DeShazo and Fermo (2002) assert that conjoint methods can obtain more information at higher quality and lower costs than contingent valuation methods for service delivery programs. The data can provide planning information for agencies that deliver services, establish appropriate service levels and tariffs, balance service quality and price, and determine appropriate levels of service attributes to offer to customers (Hensher et al., 2004). By assessing the economic and non-economic criteria that consumers 
use to determine whether to pay for WSS, program designers can create policies to increase demand for WSS.

The use of conjoint methods is not new to infrastructure service industries. ${ }^{2}$ Service attribute quantification has been common among the electricity industry for some time, with information on the value of reliability to customers used to design appropriate services and tariffs (Eto et al., 2001). In service delivery programs, we can think of conjoint analysis as a tool to determine what combination of attributes consumers will most likely purchase. Hensher et al. (2004) assess the value that households in Canberra, Australia, place on drinking and wastewater attributes. Respondents to their surveys valued attributes of WSS such as reliability of water services in addition to cost. They find evidence that customers place value on operational procedures within the water industry.

Estimation of demand for WSS and evaluation of differences in household preferences across sociodemographic groups typically requires at least three types of data that vary across the sample: (a) access and quantity of WSS, (b) price, and (c) socio-demographics. Given the variety of situations and scenarios that are considered for policy design and evaluation, researchers have used both stated preference (SP) and revealed preference (RP) methods to assess demand and understand preferences. SP approaches use data from surveys that describe potential scenarios to estimate the ex-ante demand for goods and services such as WSS. The contingent valuation and conjoint analysis methods are examples of SP approaches. RP approaches use behavioral data, often from surveys, to estimate ex-post demand for WSS. The hedonic price, averting and coping models are examples of RP approaches. In the case of WSS services, consumer data (RP data) typically does not contain enough variation across households to estimate the value of individual service attributes. Instead, water policy analysts can use stated preference methodologies such as conjoint surveys to understand the importance of service delivery attributes and cost to consumers of WSS and the extent to which consumers are willing to make trade-offs between service attributes and cost.

2 Mercer and Snook (2004) farmers' preferences for land use systems through conjoint analysis. In their study, conjoint analysis is used to determine how farmers value different attributes of land use systems and to estimate how these values affect management decisions. The researchers use this information to design land use systems that are most likely to be adopted by farmers. 
As DeShazo and Fermo (2002) suggest, when conjoint analysis is applied, several design issues and options such as service definition and payment method need to be considered at the outset (see Pattanayak et al., 2001 and 2004 for a full discussion of design choices including survey and elicitation methods). This includes: (a) defining the commodity primarily involved (b) determining the type of WSS offered and how it differs substantively from current options, and (c) characterizing the institutional setting that is providing the service. Usually a careful review of existing levels of service and alternatives can identify and define the appropriate commodity for the study. In general, preparatory activities and focus groups can uncover important features of the selected service option(s) such as metering, hours of supply, and water quality. These can then be presented in detail in the descriptive/informational parts of the conjoint survey.

The scenario, or institutional setting, must also be adapted to local conditions. In general, if certain elements of the scenario are expected to substantively affect household demand for improved services, these elements become design features that vary across the surveyed households. Surveys with these different versions would be administered and econometric modeling could be used to detect whether the private versus public institutional context affects household demand and choices.

Payment methods, in other words, how individuals are asked to pay for the services, is also an important consideration. In the water and sanitation sector, the main approach is to ask the valuation question(s) from an ex ante perspective such as increments to current bills or new bills. For households without a connection, the payment method may be a connection charge plus an increment to monthly bills. The ranges of the connection charge and monthly bill should be sufficiently wide to estimate demand and to capture relevant policy alternatives (e.g., cross-subsidization). The relative advantages of different payment method alternatives depend importantly on the target population and on the policy context. If cash income is a binding constraint for the poor, households could be asked to consider paying for service access and improvements in terms of labor as suggested by Estache et al. (2002). The preference for one alternative over another should also depend on which payment scenario is most realistic from a policy perspective.

When a high degree of uncertainty surrounds the policy design for WSS delivery, conjoint methods offer a flexible way to evaluate several institutional, service quality, tariff structure, and subsidy options simultaneously. Estache et al. (2002) provide a long list of policy instruments to address access and 
affordability for infrastructure services such as cross-subsidization, credit lines, more frequent billing, and pre-payment, among others. The researcher can determine whether these are culturally and politically palatable and technically feasible in the study area. Consultations with local experts and key informants and focus groups with the target population can be used to screen and short-list the service attributes, payment mechanisms, and institutional settings to be considered in the conjoint questions. As suggested by the experimental design literature (Black, 1999) and the findings of DeShazo and Fermo (2002), there are limits to the number of design features that can be evaluated. Elements can be chosen based on logistical constraints of survey implementation, statistical efficiency, and policy significance.

\section{Econometric Model}

Random utility theory provided the framework for understanding household choices among the proposed alternatives. As discussed in detail below, we asked households to consider five-attribute scenarios using conjoint methods: (a) monthly water bill, (b) hours of supply, (c) water quality, (d) volumetric consumption, and (e) service alternatives. We estimate preferences with a Random Utility Model (RUM), including both conditional and mixed or random-parameters logit. The RUM model assumes the utility associated with a particular choice alternative is expressed as a function of individual characteristics and the attributes of the alternative. Under the assumptions of the RUM model, individual indirect utility is expressed as a function of WSS service attributes and personal characteristics:

$$
U_{j t}^{i}=V^{i}\left(X_{j t}, Z^{i}, p_{j t} ; \beta^{i}, \delta^{i}\right)+e_{j t}^{i}
$$

where

$\mathrm{U}_{\mathrm{jt}}^{\mathrm{i}}$ is individual $\mathrm{i}$ 's utility for a WSS alternative, where $\mathrm{j}$ denotes the 4 WSS alternatives in each choice set, and $\mathrm{t}=1,2$, and 3 is the number of choice questions;

$\mathrm{V}^{\mathrm{i}}(\cdot)$ is the nonstochastic part of the utility function;

$\mathrm{X}_{\mathrm{jt}}$ is a vector of attribute levels for the WSS alternative;

$\mathrm{Z}^{\mathrm{i}}$ is a vector of personal characteristics;

$\mathrm{p}_{\mathrm{jt}}$ is the cost of the alternative;

$\beta^{\mathrm{i}}$ is a vector of attribute parameters;

$\delta^{i}$ is the marginal utility of money; and

$\mathrm{e}_{\mathrm{jt}}^{\mathrm{i}}$ is a disturbance term.

The linear specification of utility for the four alternatives is 


$$
\begin{aligned}
& U_{j t}^{i}=V_{j t}^{i}+e_{j t}^{i}=\gamma_{0}^{i}+e_{j t}^{i} \quad j=0 \\
& U_{j t}^{i}=V_{j t}^{i}+e_{j t}^{i}=X_{j t} \beta^{i}+p_{j t} \delta^{i}+e_{j t}^{i} \quad j=1,2,3
\end{aligned}
$$

where $U_{j t}^{i}, j=0,1,2,3$ is the utility of each of the three WSS alternatives. $U_{0 t}^{i}$ is the utility of the opt-out choice, which in a simple model is just $\gamma_{0}$, an alternative-specific constant for the opt-out choice. The utility of WSS Alternative A is $\mathrm{U}_{1 \mathrm{t}}^{\mathrm{i}}$ and the utility of Alternative $\mathrm{B}$ is $\mathrm{U}_{2 \mathrm{t}}^{\mathrm{i}}$.

Stochastic utility maximization asserts that individual $\mathrm{i}$ will choose alternative $\mathrm{j}$ from among the full set of available alternatives $\mathrm{K}$ if, and only if, alternative $\mathrm{j}$ provides a higher overall level of utility than all other alternatives in the choice set. ${ }^{3}$ Assuming the disturbance term follows a Type I extreme-value error structure, the probability that alternative $\mathrm{j}$ will be selected from choice set $\mathrm{t}$ is the standard conditionallogit expression:

$$
\operatorname{Pr} o b\left[C_{t}^{i}=j\right]=\frac{\exp \left(V_{j t}^{i}\right)}{\sum_{k=0}^{3} \exp \left(V_{k t}^{i}\right)}
$$

where $C_{t}^{i}$ is the selected alternative in each of 3 choice sets and $V_{j t}^{i}$ is the determinate part of the utility of alternative j. ${ }^{4}$ The probability that an alternative will be selected is the ratio of the exponentiated utility that alternative provides, relative to the exponentiated sum of the utilities that each alternative in the choice set provides. Individual characteristics do not vary among choices, and thus must be interacted with WSS attributes or alternative-specific constants.

The conditional logit model specified by Eqs. (4.2) and (4.3) is estimated using maximum-likelihood. That is, given the characteristics of the alternatives in the choice sets presented to the respondents, the

${ }^{3}$ Mathematically, individual $\mathrm{i}$ will choose alternative $\mathrm{j}$ from among the set of alternatives $\mathrm{K}$,

$$
\text { if } \mathrm{U}_{\mathrm{jt}}^{\mathrm{i}}>\mathrm{U}_{\mathrm{kt}}^{\mathrm{i}} \text { for all } \mathrm{j} \text { in } \mathrm{K}, \mathrm{j} \neq \mathrm{k}
$$

substituting for $\mathrm{U}_{\mathrm{jt}}^{\mathrm{i}}$ from Eq. (4.1), and rearranging terms we have

$$
\mathrm{V}_{\mathrm{jt}}^{\mathrm{i}}-\mathrm{V}_{\mathrm{kt}}^{\mathrm{i}}>\mathrm{e}_{\mathrm{kt}}^{\mathrm{i}}-\mathrm{e}_{\mathrm{jt}}^{\mathrm{i}}
$$

${ }^{4}$ The basic exposition of the properties of this model can be found in McFadden (1981). 
model estimates coefficients that maximize the likelihood that we would observe the actual choices in the sample. Thus, the coefficients show the relationship between the probability of selecting an alternative and the attributes of that alternative.

Conditional logit models are known to be subject to violations of the restrictive "independence of irrelevant alternatives" (IIA) assumption. This condition requires that the ratio of probabilities for any two alternatives be independent of the attribute levels in the third alternative. If IIA is violated, parameter estimates are biased. Second, the conditional logit models assume that differences in respondents' tastes are fully accounted for in the model specification and thus differences in value to respondents arise only from differences in probability of selecting choice alternatives. Finally, conditional logit does not account for correlations within each subject's series of choices.

Revelt and Train (1998) have proposed using random-parameter or mixed logit for stated preference data. Mixed logit is not subject to the IIA assumption, ${ }^{5}$ accommodates correlations among panel observations, and accounts for unobserved heterogeneity in tastes across subjects.

Modifying Eq. (4.2) to introduce subject-specific stochastic components for each $\beta$,

$$
\begin{aligned}
& U_{j t}^{i}=V_{j t}^{i}+\mathrm{e}_{j t}^{i} \equiv\left(V_{0}^{i}+\eta_{0}^{i}\right)+\mathrm{e}_{j t}^{i} \quad j=0 \\
& U_{j t}^{i}=V_{j t}^{i}+\mathrm{e}_{j t}^{i} \equiv X_{j t}\left(\beta+\eta^{i}\right)+\delta^{i} P_{j t}+\mathrm{e}_{j t}^{i} \quad j=1,2,3
\end{aligned}
$$

Eq. (4.3) now becomes

$$
\operatorname{Pr} o b\left[C^{i}=\left(C_{j 1}^{i}, C_{j 2}^{i}, \ldots, C_{j 6}^{i}\right)\right]=\prod_{t=1}^{6}\left[\frac{\exp \left[V_{j t}^{i}\left(\beta^{*}\right)\right]}{\sum_{k=0}^{3} \exp \left[V_{k t}^{i}\left(\beta^{*}\right)\right]}\right]
$$

where now $\beta^{*}=\left(\beta+\eta^{i}\right)$. In contrast to conditional logit, the stochastic part of utility now may be correlated among alternatives and across the sequence of choices via the common influence of $\eta^{i}$. McFadden and Train (2000) show that any RUM model can be approximated by some mixed logit specification.

${ }^{5}$ Technically, this is only true when the definition of one or more stochastic effects is shared across alternatives. 


\section{The Sri Lanka Application}

\section{Design of the Conjoint Questions}

In Sri Lanka, we used focus groups, purposive interviews and meetings with officials to determine which attributes of the contingent service, other than cost, were likely to affect household demand for improved services. We identified three attributes: volume of consumption, hours of supply, and water quality. Volume of consumption is defined as the number of liters available per person per day. Hours of supply refers to the hours a customer would receive water service with good pressure. Finally, the water quality included 5 levels of treatment, with the best being water that was safe to drink straight from the tap and the worst being water that needed to be boiled, filtered and treated with chemicals. The policy community was also interested in the service alternatives to piped water supply including mini-grids and public stand posts. Thus, we asked households to consider five-attribute scenarios using conjoint methods, where the attributes included: (a) monthly water bill, (b) hours of supply, (c) water quality, (d) volumetric consumption, and (e) service alternatives. Table 1 shows each of the 5 attributes and the levels for each attribute.

After defining the attributes, we created the experimental design. We used what is called a labeled design (Louviere et al. 2000). In a labeled design, each choice question contains an alternative for each "label". 6 In this case, the "labels" were the service alternatives (private tap, mini-grid, and public stand post), and we created a WSS service option for each of the service alternatives. Table 2 presents a sample conjoint question from the survey. If respondents expressed difficulty in choosing, after several prompts they were told that they could choose none of the plans. These respondents were coded as "opt-out" or preferring their current service to those offered. To create the experimental design, we employed an adaptation of Zwerina, Huber, and Kuhfeld's (1996) algorithm to search for a D-optimal experimental design. D-efficiency minimizes the geometric mean of the covariance matrix of the parameters and is the most commonly used criterion for constructing experimental designs (Kanninen, 2002). There were 27 unique tradeoff tasks grouped into 9 blocks; each respondent saw one block of 3 choice tasks with four alternatives each. Eighteen hundred respondents answered a total of 5,404 questions (that generated 21,616 observations - yes/no answers for the three alternatives and the opt-out option in each question).

6 In an unlabeled design, all the attributes are varied randomly. In our survey, this would mean that the attribute "service alternative" would be varied just like the other attributes and the number of options presented in each choice question would not have to equal the number of service alternatives (for more details see Louviere et al. 2000). 
In all SP studies, the main challenge is to persuade the respondent to seriously consider a proposal, typically to be delivered at some point of time in the future. We found respondents to be willing to look ahead and earnestly consider the commodity-improved water supply. This is presumably because water supply is a serious issue that commands people's time and attention and because the scenario we presented was credible. The credibility of the scenario could stem from the fact that many households seemed to have heard about plans to expand the water supply network in the area. The local population's willingness to understand and consider our proposed scenarios was a valuable signal regarding the content of the survey instrument and the feasibility of the conjoint approach.

\section{Survey administration}

The data come from a 2003 survey of 1800 households in the Greater Negombo and the coastal strip from Kalutara to Galle in Southwest Sri Lanka. This survey was implemented to gauge current water and sanitation conditions, estimate household demand, and assess access and affordability of poor households before reform measures were implemented. A 3-stage stratified random sampling approach was used to select our sample (see Pattanayak et al. 2004 for more details on how we selected our sample). Our survey instrument was developed through a series of focus groups (in Kandy, Galle, and Kalutara); several purposive discussions with households, the National Water Supply and Drainage Board officials, and the Water Sector Reform Unit staff; and 120 pre-tests in Negombo, Kalutara and Peradeniya. The final 69-page survey contained 7 modules, with a split sample design on the contingent valuation and conjoint questions to gauge household demand. The seven modules included: location and policy priorities; water sources; water treatment, storage and hygiene; sanitation and sewerage; contingent valuation; family roster and health; and a socio-economic profile.

Enumerators were selected from a pool of recent Peradeniya graduates and trained using a mix of lectures, role-plays and field trials in the final survey area. Each survey was conducted as an in-person interview that lasted approximately 50 minutes. The survey process was completed in 2 months. 


\section{Empirical Findings}

\section{Sample Data}

In Table 3 we report descriptive statistics for the overall sample (more detail is contained in Pattanayak 2005a). Table 3 shows that 89 percent of the sample is Sinhalese and 62 percent is Buddhist. The average family size is 4.8 members, with 1.3 children under 18 years of age. The typical household head is 52 years old and has 10 years of education. Over 90 percent of households have adults who have completed primary education and almost all households send their school-aged girls to school.

To compare poor and non-poor households, we first need to define these distinctions. The Sri Lanka Department of Census and Statistics identifies poor households using data on household expenditures from the Household Income and Expenditure Survey (HIES, Sri Lanka Department of Census and Statistics 2002). In order to be able to compare our results to the Census data, we also identified poor households through monthly consumption expenditures. ${ }^{7}$ Using the data, we classified our sample based on monthly per capita consumption deciles. Poor households comprise the bottom two deciles, or quintile, of the distribution (or households who spend less than or equal to Rs. 3,356 per capita per month are poor). By this definition, 365 of our sample households are classified as poor, of which 124 live in the Greater Negombo and 241 live in the Kalutara-Galle strip. This definition of the poor not only allows us to explore poverty relative to the overall socio-economic distribution, but also enables us to directly compare our results with other regions and countries if necessary. Table 3 also contains descriptive statistics for the poor and non-poor sub-samples.

Major sources of water for our sample households were private connections to the piped water network, private wells, and water from neighbors. Households indicated that their dwellings are close to the piped water network. A typical household can access at least three sources, with approximately 54 percent of households claiming that they could get their water from a private piped connection if they wanted. Typically, a household uses just one source of water. Only about 4 percent of the sample relies exclusively on a combination of community sources-including neighbors, public taps, and public wells.

7 Our consumption survey module focused on major items and not all the micro details covered in the HIES. We made three adjustments to our consumption data - calibrated our food expenditure, imputed our housing expenditure and adjusted our 'other expenditure' category - allowing us to define poverty in a manner that was comparable to the Sri Lankan government's official statistics. 
Figure 1 shows the location of households in and around the three towns of Negombo, Kalutara and Galle. We distinguish the households by poverty status (poor, non-poor) and water source type (private tap, well, neither) [Pattanayak et al., 2005b]. Most households felt that water from private connections, private wells, and neighbors is clean, tastes fine, does not smell bad, or pose any serious health problems. However, water from private connections was deemed to be irregular and unreliable.

The results show that 'self-provision' through private wells is a substantive and realistic alternative to tap water, even for poor households. This finding was also confirmed by opinions of households who are currently not connected to the piped water network. In general, households are satisfied with their existing sources. By choice or through compulsion, private wells appear to be the dominant form of self-provision.

When asked to rank water supply problems, 24 percent believe that 24 hours per day service is most important; whereas 17 percent believe that faster processing of connections to the piped network is critical. Twenty-four percent believe that there are no water supply problems. Almost 90 percent of the households believe that the government should provide subsidized connections to the piped network for poor households. In general, they believe that the subsidy should be as much as 50 percent of the connection cost.

Over 40 percent of households treat their water before drinking and cooking by either boiling and/or filtering. Forty-three percent of households have one or more storage tanks with a median capacity of 750 liters at a cost of Rs. 5,000. Over 80 percent of the households have protected containers for water used in drinking and cooking, and an equally large percentage of households handle and transfer water without dipping into the storage container.

These results clearly suggest that water supply is viewed as a 'quantity' issue at best, and certainly not a quality issue for the majority of the population. In stark contrast, sanitation problems are clearly associated with contamination and public health risks.

In evaluating the health status of our sample we find that one percent of the households have experienced a case of diarrhea in the month prior to the survey. Only about 2 percent of the entire sample of households has experienced a morbidity event related to water-borne or water-washed diseases in the past 
year. About 3 percent have experienced a mortality event in the past year, with only about one percent reporting mortality of a child.

Since diarrhea is the primary public health disease of concern with respect to WSS interventions, we developed a profile of households who have had diarrhea cases and compare them to households who have not suffered from diarrhea in the month prior to the survey. On average, the 'diarrhea households' are poorer, more likely to have children under 5, and less educated. In general, they are less likely to be connected to the piped water network, and consume about 30 percent less water per month. They are less likely to store the water in overhead tanks, transfer water by pouring or using spigots, and wash their hands before eating and before preparing food. In terms of toilet behaviors, they are less likely to wash their hands in or just outside the toilet, use appropriate technologies for hand washing, and sanitarily handle and dispose children's feces.

\section{Econometric Estimates}

As the sample characteristics above demonstrate, the poor generally experience WSS services differently than the non-poor. In a stated preference study on provider choice for malaria treatment in Nepal, preferences varied significantly based on whether the household was poor. In addition, cost was the major determinant of provider choice and the poor are most cost sensitive (Morey et al. 2003a). The heterogeneity of preferences among respondents represents a challenge for estimating welfare impacts using the results of the SP conjoint questions. Morey et al. (2003b) provide a method of estimating consumer surplus when exact information on income is missing. Here we consider how attributes affect demand and if poor households are different in their preferences for service attributes. We also consider non-linearities for continuous attributes, such as hours of supply and volume of consumption.

Table 4 presents the results of the conjoint analysis used in our Sri Lanka study. This table confirms that households care about attributes of the service, other than costs. A positive coefficient on any particular attribute indicates that the attribute generates positive utility such that higher levels of that attribute (e.g., greater volume of water) are preferred to lower levels of the same attribute. Similarly a negative coefficient indicates that the attribute generates negative utility such that lower levels of that attribute (e.g., smaller monthly bills) are preferred to higher levels. We also evaluated whether poor households have different preferences for any of these attributes. This is accomplished by multiplying each service attribute variable with a dummy variable representing poor households and evaluating whether the interaction variable is statistically significant. 
As discussed above, respondents could choose one of 4 options: private tap, mini-grid, public stand posts and opt-out. The regression equation included alternative specific constants for each of the 4 options. The coefficients on the dummy variables representing the service alternatives paint an interesting picture. The estimated coefficients, as reported in Table 4, show that private taps and mini-grids are preferred to public stand posts. They also show that households prefer their current option (represented by the choice to opt out and not choose any of the three options provided) to all three service alternatives proposed. In general, households would prefer to obtain the improvements in hours, volume, and safety under their existing option. In total, opt-out was selected in $45 \%$ of the choices. It should be noted that the alternative specific constants represent some inherent attribute of the service options separate from costs, volume, safety, and hours. For example, privacy may be one of the inherent attributes of a private tap connection. Similarly convenience and familiarity may be other attributes. The coefficients on the dummy variables measure some combination of all these residual attributes that were not captured by the other attributes, but apply to that particular service alternative.

The interaction terms for each of these coefficients and the poor sub-sample allow us to investigate if poor households have different preferences for these attributes. The p-values as well as the chi-square statistics suggest that these coefficients are statistically significant as a group. However, only a few of the individual interaction terms are statistically significant. This suggests that the poor hold different preferences only with regards to some attributes. We see that the preferences of the poor are essentially no different in terms of volume, hours, and safety. To be clear, this does not mean that they do not care about these attributes, but just that they are no different from the non-poor in this regard.

Turning to attributes that are different, we see that the poor have a higher marginal disutility for money. Presumably, this is because when income is a significant constraint, every rupee counts. Note, if the interaction term is significant, it should be added to the coefficient on the term by itself to see if the poor get more or less utility form the associated attribute. Through this process we see that the poor do not prefer private taps to public stand posts, all things considered. They do prefer mini-grids to public taps. Finally, they prefer their current options to the proposed alternatives (controlling for volume, hours, and safety). However, this preference for status quo is considerably less strong than in the case of the nonpoor. 
The mixed logit results are reported in columns 5 and 6 of Table 4. An estimate of both the parameter and the standard deviation is reported for each variable except for bill, which standard deviation is set equal to 1 to identify this model. The relative size of the standard deviation parameters relative to the corresponding point estimates indicates the degree of preference heterogeneity. In the mixed logit, a large and significant standard deviation indicates that there is considerable taste heterogeneity among the respondents.

As shown in Table 4, the overall pattern is similar between conditional and mixed logit results although individual coefficient estimates and significance levels are different. The proposed monthly bill is negative and significant as expected. Both consumption volume and supply hours generate positive utility. Consumption volume has a large and significant standard deviation, which indicates preference heterogeneity among the households (though the conditional logit model assumes that this heterogeneity is not necessarily pronounced between poor and non-poor households). Similar to the conditional logit results, supply hours show a diminishing marginal utility for increases in this attribute.

In terms of water safety variables, the coefficients are ordered as we expect. Better quality and safer water yields the highest utility, while unsafe water generates the lowest utility. Except for the safest quality water (i.e., water that you could drink "straight from the tap"), households did not seem to have diverse preferences for other levels of safety. In comparing service alternatives, the large coefficient on the status quo dummy suggests that households are happy with their current status, preferring it to all three service alternatives offered. Amongst the proposed alternatives, households rank mini-grids over private taps, and private taps over public stand posts. The large and significant standard deviations in the mixed logit model suggest households exhibit considerable heterogeneity in their preference for both private taps and mini-grids. The poor tend to value private taps significantly less than other households.

\section{Concluding Remarks}

In this paper we used conjoint analysis to research the preferences of the poor and non-poor regarding alternative WSS programs. The data from the Sri Lanka study demonstrates how conjoint analysis can provide information to aid in the design and evaluation of WSS programs. Findings from our research in Sri Lanka suggest that consumers are interested in attributes other than costs and that demand for services will be reflected in their provision; that poor and non-poor households place similar values on water 
service attributes; and that the methodology of conjoint analysis can provide insightful information for the design and evaluation of WSS programs.

Both the conditional and mixed logit results conform to expectations that consumption charges decrease utility, whereas volume, safety, and hours of supply increase utility (the impact is non-linear for hours of supply $)^{8}$. Another way to evaluate the relative importance of these attributes is to convert the marginal utilities into money terms. That is, we can divide the estimated coefficients by the marginal utility of money (which is the coefficient on the consumption charge variable) to derive willing to pay for marginal improvements in these attributes. The models also show that private taps and mini-grids are preferred to public taps, but that status quo is preferred to many of the alternatives. In addition, the mixed logit results indicate diverse preferences among the households in terms of quantity and service options, but not supply hours and safety (except the highest level of safety). The interaction terms show that the poor are no different in terms of preferences for volume, safety, and hours of supply. However, consumption charges are a source of greater disutility for the poor. Perhaps the most interesting finding is that the poor do not necessarily prefer private taps to public taps or mini-grids and that they are less satisfied with the status quo.

Implications of these results are that demand for WSS will be influenced not only by the costs of service but also by the ability of the program to provide an expected level of volume, quality, and hours of supply. If provision of these service attributes is inefficient, consumer demand will decrease. If we find that preferences of poor households are similar to those of non-poor households, similar service program options can be offered, lowering transaction costs for the service delivery program. However, as expected, demand by poor households will be more price sensitive. In addition, we find that demand for piped water supply alternatives is low; most households prefer their current option to the piped water service alternatives presented. Thus the feasibility of implementing a water supply service delivery program that requires huge investments and significant price increases are unlikely to attract large numbers of customers in the study area.

8 The non-linear impact of hours of supply shows that households value additional hours of supply to a certain level, in this case $19-20$ hours per day, but value any additional hours above this level less. 
Another important implication of this study is that empirical findings support the usefulness of the conjoint analysis methodology. We introduced the basic methodology of conjoint analysis and how it can be used as a tool to understand consumer preferences in the water and sanitation sector. We have also identified challenges of using the methodology and provided suggestions on how these challenges can be minimized. The primary weakness of the SP approach is often cited to be its hypothetical nature.

Respondents are placed in unfamiliar situations in which complete information is not available. At best, respondents give truthful answers that are limited by their unfamiliarity. At worst, respondents give trivial answers due to the hypothetical nature of the scenario. Based on the Sri Lanka study, we feel that respondents were able to process information presented in the conjoint analysis questions and provide insightful answers.

Future microeconomic studies of water and sanitation programs should give more attention to understanding multiple water policy attributes and their affect on consumer demand. While the conjoint methodology requires a more complex experimental design and analysis techniques than contingent valuation methods, the subsequent results allow for more accurate analysis of the real-life water and sanitation situation. Our example has shown one application of conjoint analysis and how surveys prior to program implementation can aid in program design, theoretically improving access and demand of WSS for both poor and non-poor households. Ex ante analysis of consumer preferences would also be valuable for project design and evaluation. With concerns over access and affordability of poor households, another use of conjoint analysis is to evaluate preferences across sub-populations. This information allows service delivery programs to do two things: explicitly target user groups and improve service demand, both lowering transaction costs. The impact of different water policy tools (e.g. subsidies, provision of credit, vouchers, and targeted tariff structures) given preferences and income of customers could be estimated on a case-by-case basis. 


\section{References}

Adamowicz, W.L., P.C. Boxall, J.J. Louviere, J. Swait and M. Williams. Stated Preference Methods for Valuing Environmental Amenities. in Valuing Environmental Preferences: Theory and Practice of the Contingent Valuation Method in the U.S., E.C. and Developing Countries. I. Bateman and K. Willis, editors. Oxford University Press, 1999:460-479.

Black, T.R. 1999. Doing Qualitative Research the Social Sciences: An Integrated Approach to Research Design, Measurement and Statistics. London: Sage.

Bosch, C., K. Hommann, G. Rubio, C. Sadoff, and L. Travers. 2000. Water and Sanitation. Chapter 23 in A Sourcebook for Poverty Reduction Strategies Volume 2, pages 371-404. Washington, D.C.: World Bank.

Cattin, Philippe, and Wittink. 1982. Commercial Use of Conjoint Analysis: A Survey. Journal of Marketing 46:44-53.

DeShazo, J.R. and G. Fermo. 2002. Designing Choice Sets for Stated Preference Methods: The Effects of Complexity on Choice Consistency. Journal of Environmental Economics and Management 44: 123143.

Estache, A., V. Foster, and Q. Wodon. 2002. Accounting for Poverty in Infrastructure Reform: Learning from Latin America's Experience. WBI Development Studies No 23950.

Eto, J., J. Koomey, B. Lehman, N. Martin, E. Mills, C. Webber, and E. Worrell. 2001. Scoping Study on Trends in the Economic Value of Electricity Reliability to the U.S. Economy. Technical Report, Energy Analysis Department, Lawrence Berkeley Laboratory, Berkeley California.

Harrison, G. and J. List. 2004. Field Experiments. Journal of Economic Literature XLII: 1009-1055, December.

Hensher, D., N. Shore, and K. Train. 2004. Households' Willingness to Pay for Water Service Attributes. Unpublished manuscript.

Kanninen, B. 2002. "Optimal Design for Multinomial Choice Experiments," Journal of Marketing Research 39:214-227. 
Louviere, J., D. Hensher, and J. Swait. 2000. Stated Choice Methods: Analysis and Application. Cambridge University Press, Cambridge, U.K.

Manski, C. 1977. The structure of random utility models. Theory and Decision 8: 229-254.

McFadden, D. 1976. The Revealed Preferences of a Government Bureaucracy: Empirical Evidence. Bell Journal of Economics 7: 55-72.

McFadden, D., and K. Train. 2000. Mixed MNL Models for Discrete Response. Journal of Applied Econometrics 15(5):447-470.

Mercer, E. and A. Snook. 2004. Analyzing Ex-Ante Agroforestry Adoption Decisions With Attribute Based Choice Experiments. In Valuing Agroforestry Systems, J.R.R. Alavalapati and D.E. Mercer (eds.), Kluwer Academic Publishers, Netherlands, Ch. 6, pp. 237-256.

Morey, E.R., V. R. Sharma, and A. Karlstrom. 2003a. A simple method of incorporating income effects into Logit and Nested-Logit models: theory and application. American Journal of Agricultural Economics 85(1), 250-255, February.

Morey, E.R., V. Sharma, and A. Mills. 2003b. Estimating Malaria Patients' Household Compensating Variations for Health Care Proposals in Nepal. Social Science and Medicine 57 (2003) 155-165.

Pattanayak, S.K., J.-C. Yang, D. Whittington, B. Kumar, G. Subedi, Y. Gurung, K. Adhikari, D. Shakya, L. Kunwar, and B. Mahabuhang. 2001. Willingness to Pay for Improved Water Services in Kathmandu Valley. Submitted to the World Bank, Water and Sanitation Program, August.

Pattanayak, S.K., E. O. Sills, and D. Whittington. 2004. "Water supply coverage and cost recovery in Kathmandu: Understanding the role of time preferences and credit constraints." RTI Working Paper. RTI Working Paper.

Pattanayak, S.K., J.-C. Yang, K.M. Jones, C. van den Berg, H. Gunatilake, C. Agarwal, H. Gunatilake, H. Bandara, and T. Ranasinghe. 2005a. Poverty Dimensions of Water, Sanitation, and Hygiene in Southwest Sri Lanka. RTI Working Paper.

Pattanayak, S.K., E. Sills, L. Carrasco, J.-C. Yang, C. van den Berge, C. Agarwal, H. Gunatilake, H. Bandara, and T. Ranasinghe. 2005b. The Economic Geography of Water and Poverty: Evidence from Southwest Sri Lanka. RTI Working Paper. 
Revelt, D., and K. Train. 1998. Mixed Logit with Repeated Choice: Households' Choices of Appliance Efficiency Level. The Review of Economics and Statistics 80:647-657.

Ryan, M., Scott, D.A., Reeves, C., Bate, A., van Teijlingen E.R., Russell,E.N., Napper, M. and Robb, C.M.. 2001. Eliciting public preferences for health care: a systematic review of techniques.

HealthTechnology Assessment 5(5).

Sri Lanka Department of Census and Statistics. 2002. 2002 Household Income and Expenditure Survey. $<$ http://www.statistics.gov.lk/samplesurvey/inex/index_final\%20report.htm>.

Zwerina, K., J. Huber, and W.F. Kuhfeld. 1996. A General Method for Constructing Efficient Choice Designs. SAS Working Paper. Available at

$<$ http://citeseer.nj.nec.com/rd/89088587.376089.1.0.25.Download/http:qSqqSqftp.sas.comqSqtechsupqSq downloadqSqtechnoteqSqts629.pdf>.

World Bank. 2004. Drinking water, sanitation, and electricity. World Development Report. 


\section{Acknowledgements}

The authors would like to acknowledge the contributions of H. Gunatilake, C. Agarwal, H. Bandara, T. Ranasinghe, G.G. Jayasinghe and all 13 field enumerators, including S.M. Chandrakanthi, Erandathi Jayasinghe, Lalith Sudusinghe, Madhupani Samaratunge, Preethi Thushari Kulatunga, Sandhya Wickramaratne, Suranga Jayasundara, Kapila Abayasinghe, Suminali Gunatilake, Champika Roshan, Lalani Darmamala Ranawake, Chalani Indika Attanayake, and Thusitha Gunarathna in the data collection. The authors are grateful to Clarissa Brocklehurst; and Cate Corey for her help with the literature review, design of health modules, and proof-reading. Finally, we would like to thank Chandra Perera (WSRU), Shanta Fernando (NWSDB), U. Ratnapala (WSRU), Chrishan Fernando (NWSDB) and Rizwan (NWSDB) for their help during the design and implementation phases of this study. Financial support from the Bank-Netherlands Water Partnership for Water Supply and Sanitation (BNWP-WSS) a facility that enhances World Bank operations to increase delivery of water supply and sanitation services to the poor, is gratefully acknowledged. The opinions reflected in this paper do not represent the opinions of the World Bank, RTI International, or the BNWP-WSS. 
Figure 1. Household Locations, Poverty Status and Water Source Type

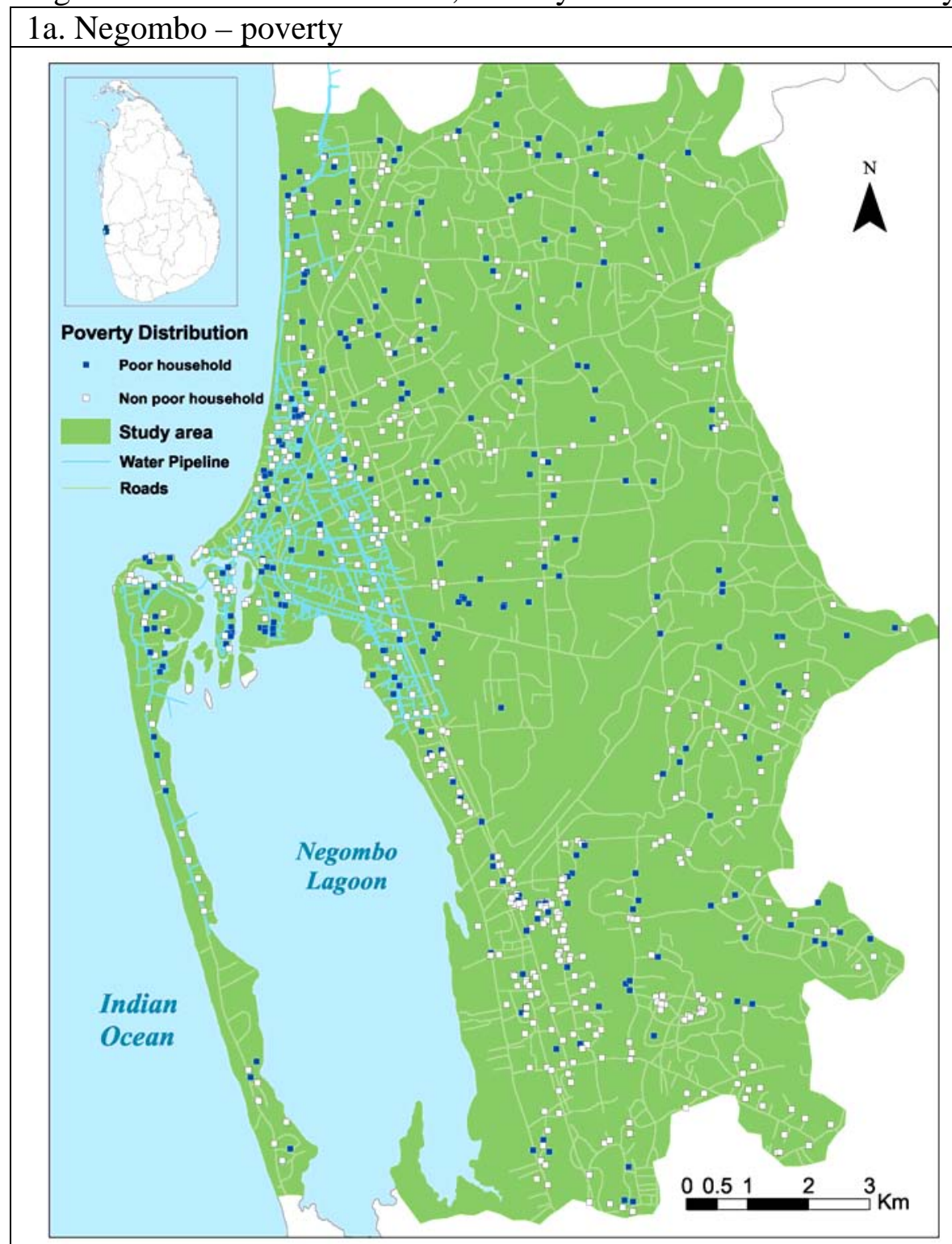

1b. Negombo - private connection to piped water

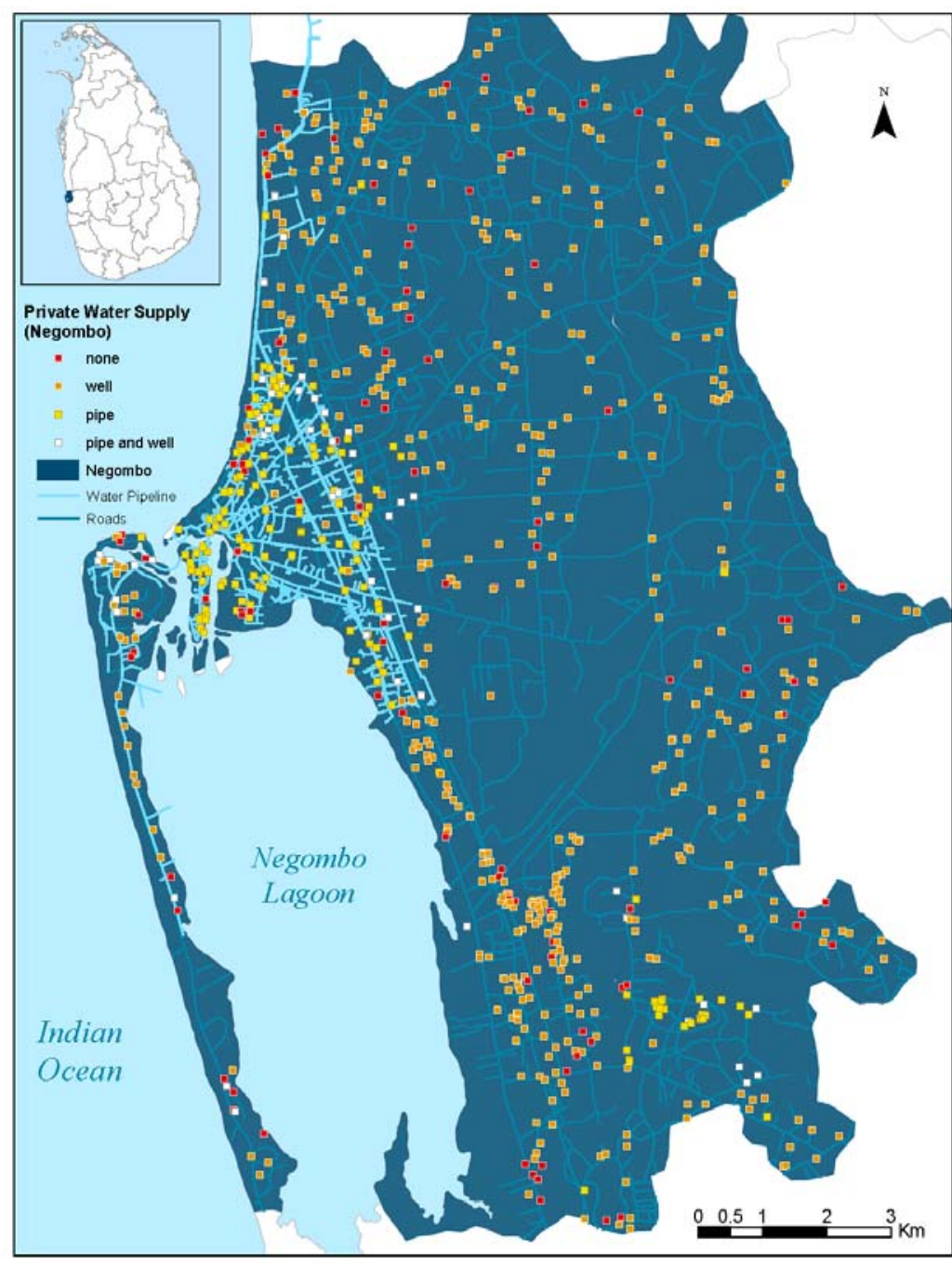




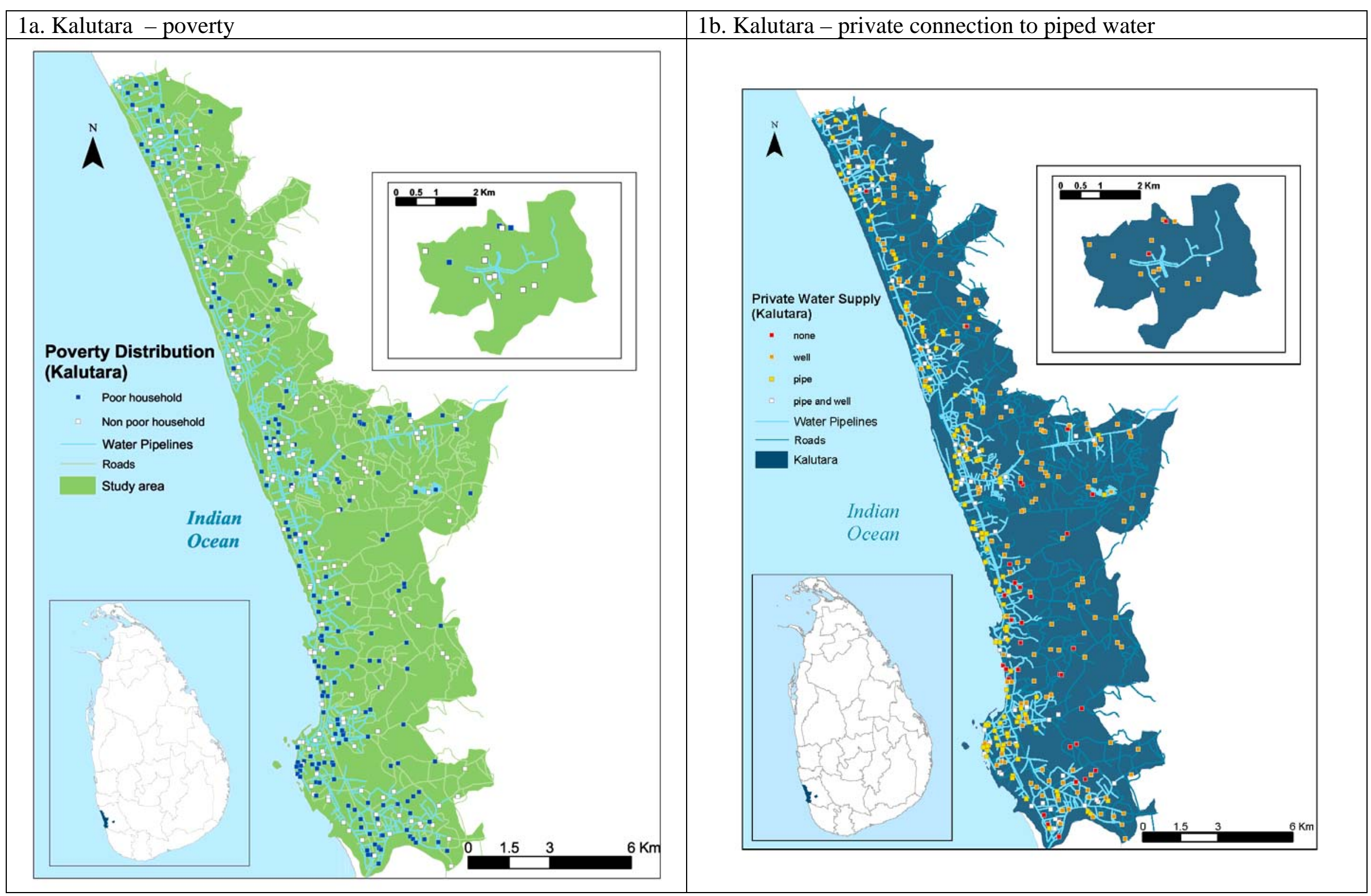




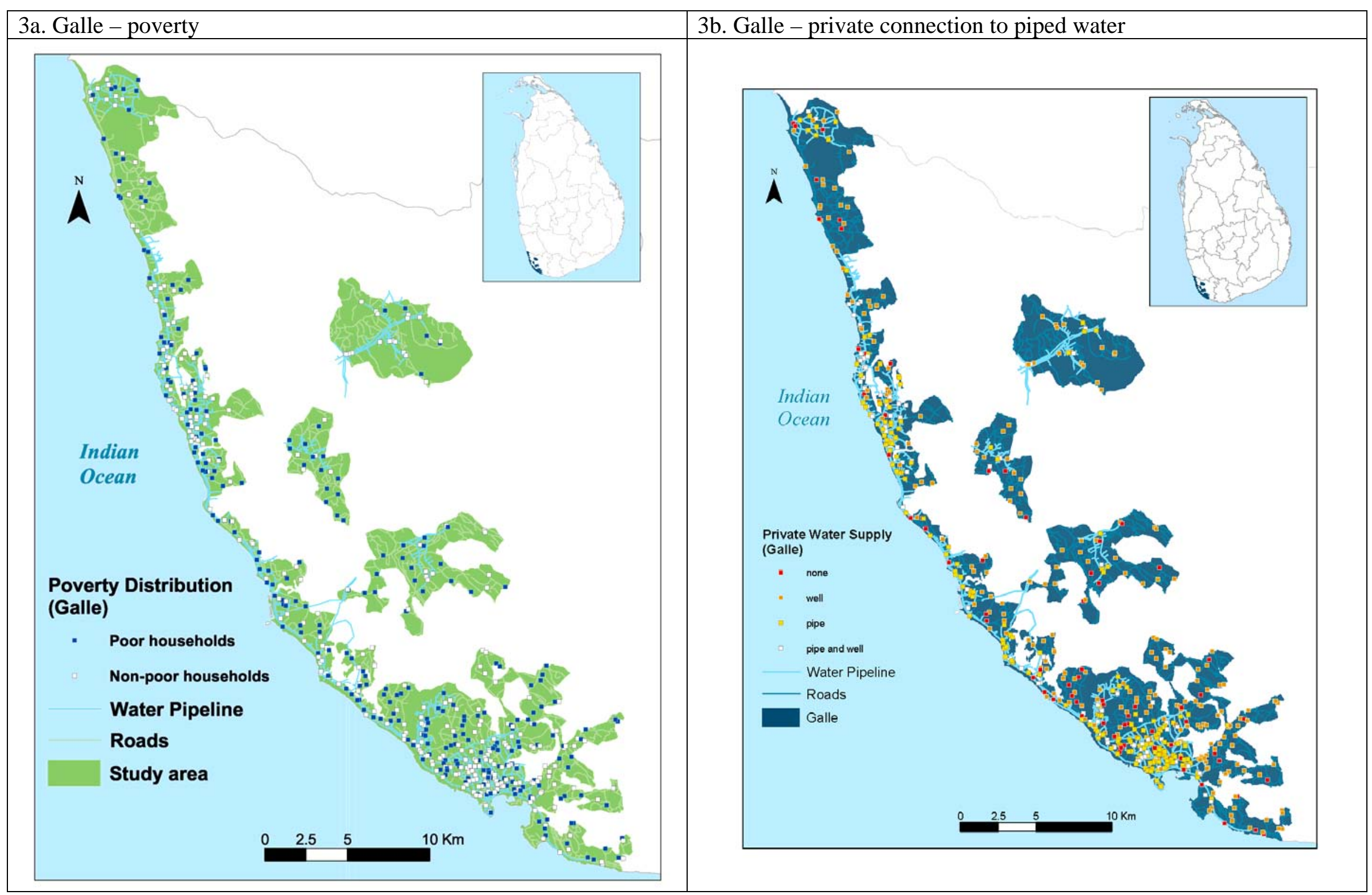


Table 1. Water Supply Service Attributes and Levels

\begin{tabular}{|c|c|c|c|}
\hline Attribute & \multicolumn{3}{|c|}{ Levels } \\
\hline Service option & Private water connection & Small diameter mini-grid & Metered standpost \\
\hline Consumptive volume & $\begin{array}{l}600 \text { liters per day } \\
800 \text { liters per day } \\
1000 \text { liters per day }\end{array}$ & $\begin{array}{l}200 \text { liters per day } \\
600 \text { liters per day } \\
1000 \text { liters per day }\end{array}$ & $\begin{array}{l}200 \text { liters per day } \\
400 \text { liters per day } \\
600 \text { liters per day }\end{array}$ \\
\hline Supply hours & $\begin{array}{l}12 \text { hours a day } \\
16 \text { hours a day } \\
24 \text { hours a day }\end{array}$ & $\begin{array}{l}4 \text { hours a day } \\
12 \text { hours a day } \\
24 \text { hours a day }\end{array}$ & $\begin{array}{l}4 \text { hours a day } \\
8 \text { hours a day } \\
12 \text { hours a day }\end{array}$ \\
\hline Safety & $\begin{array}{c}\text { Straight from the tap } \\
\text { Only after filtering } \\
\text { Only after boiling }\end{array}$ & $\begin{array}{l}\text { Straight from the tap } \\
\text { Only after boiling } \\
\text { Only after boiling, } \\
\text { filtering and treating }\end{array}$ & $\begin{array}{c}\text { Only after boiling } \\
\text { Only after filtering and } \\
\text { boiling } \\
\text { Only after boiling, } \\
\text { filtering and treating }\end{array}$ \\
\hline Monthly water bill & $\begin{array}{l}200 \text { Rupees } \\
500 \text { Rupees } \\
800 \text { Rupees }\end{array}$ & $\begin{array}{l}25 \text { Rupees } \\
100 \text { Rupees } \\
600 \text { Rupees }\end{array}$ & $\begin{array}{l}25 \text { Rupees } \\
50 \text { Rupees } \\
100 \text { Rupees }\end{array}$ \\
\hline
\end{tabular}


Table 2. Sample Conjoint Task

\begin{tabular}{|l|c|c|c|}
\hline & Alternative 1 & Alternative 2 & Alternative 3 \\
\hline Service option & Private water connection & Small diameter mini-grid & Metered standpost \\
\hline Liters per day & 800 & 1000 & 600 \\
\hline Supply hours per day & 24 & 4 & 8 \\
\hline Safe for drinking & After boiling & Straight from the tap & $\begin{array}{c}\text { After filtering, } \\
\text { boiling and treating }\end{array}$ \\
\hline Monthly water bill (Rs.) & 500 & 100 & 50 \\
\hline
\end{tabular}

What do you think your household would do?

(1) keep connection to the water supply network,

(2) connect to the small diameter mini-grid,

(3) rely on the metered standpost, or

(4) would you choose none of the above and continue to use your present water sources 
Table 3. Demographics and Socioeconomics*

\begin{tabular}{|c|c|c|c|}
\hline Demographics and Socioeconomics & $\begin{array}{c}\text { Poor } \\
(n=365)\end{array}$ & $\begin{array}{l}\text { Nonpoor } \\
(n=1453)\end{array}$ & $\begin{array}{c}\text { Overall } \\
(n=1818)\end{array}$ \\
\hline \% Sinhalese & 85 & 91 & 89 \\
\hline$\%$ Buddhist & 65 & 62 & 62 \\
\hline Family size & 5.8 & 4.5 & 4.8 \\
\hline Adult equivalent & 5 & 4 & 3.5 \\
\hline \% have children under 5 & 31 & 25 & 26 \\
\hline Household head's education attainment (years) & 8 & 10 & 10 \\
\hline$\%$ have adults who have completed primary school & 86 & 95 & 93 \\
\hline \% have girls attending school & 98 & 99 & 99 \\
\hline Monthly consumption (Rs.) & 11,883 & 24,053 & 21,615 \\
\hline Monthly per capita consumption (Rs.) & 2,614 & 6,066 & 5,294 \\
\hline \% Food expenditure & 49 & 36 & 38 \\
\hline Monthly per capita food expenditure (Rs.) & 1,214 & 2,167 & 1,953 \\
\hline \% living on less than US\$ 1 a day & 67 & 0 & 13 \\
\hline \multicolumn{4}{|l|}{ Primary occupation } \\
\hline Government & 10 & 24 & 22 \\
\hline Business & 9 & 19 & 17 \\
\hline Private sector & 10 & 18 & 16 \\
\hline Manual labor & 27 & 7 & 11 \\
\hline \% received Samurdhi & 47 & 12 & 19 \\
\hline \% can borrow Rs. 3,000-5,000 relatively easily & 47 & 60 & 58 \\
\hline \multicolumn{4}{|l|}{ Housing conditions } \\
\hline \% single family and singe story & 79 & 92 & 86 \\
\hline \% have cement floor & 91 & 97 & 92 \\
\hline \% have red brick/cement walls & 81 & 97 & 94 \\
\hline$\%$ have tiled roof & 66 & 79 & 76 \\
\hline Amortized monthly housing rent (Rs.) & 1,423 & 6,642 & 4,744 \\
\hline \multicolumn{4}{|l|}{ Distance to infrastructure } \\
\hline Piped water network (kilometers) ** & 0.25 & 0.13 & 0.2 \\
\hline Main road (kilometers) & 0.2 & 0.1 & 0.1 \\
\hline
\end{tabular}

*All statistics are presented in either the percentage term or the median value.

** This 'median' statistic masks the fact that distance to the network essentially falls into three broad classes: 52 percent of the dwellings which are less than 250 meters from network; 17 percent which are less than 1000 meters from the network; and 31percent which are greater than one kilometer from the network and as much as 15 kilometers from the network. Thus, the median is 0.25 kilometers, whereas the mean is about 3.25 kilometers. 
Table 4. Attributes of Service Alternatives - Conditional and Mixed Logit Models for Conjoint Analysis

\begin{tabular}{|c|c|c|c|c|c|}
\hline \multirow[b]{2}{*}{ Variable } & \multirow[b]{2}{*}{ Mean } & \multicolumn{2}{|c|}{ Conditional Logit } & \multicolumn{2}{|c|}{ Mixed Logit } \\
\hline & & Coefficient & p-value & Coefficient & p-value \\
\hline Proposed monthly water bill (Rs.) & 216 & -0.003 & 0.000 & -0.007 & 0.000 \\
\hline Volume of water per day (liters) & 450 & 0.0004 & 0.000 & 0.001 & 0.000 \\
\hline Standard deviation & & & & 0.003 & 0.000 \\
\hline $\begin{array}{l}\text { Hours of water supply per day } \\
\text { (number of hours) }\end{array}$ & 10 & 0.039 & 0.024 & 0.144 & 0.000 \\
\hline Standard deviation & & & & 0.027 & 0.148 \\
\hline Squared hours of water supply per day & 161 & -0.001 & 0.053 & -0.004 & 0.000 \\
\hline Standard deviation & & & & 0.002 & 0.000 \\
\hline $\begin{array}{l}\text { Water is safe for drinking straight from the } \\
\text { tap }(1=\text { yes; } 0=\text { no })\end{array}$ & 0.18 & 0.840 & 0.000 & 2.006 & 0.000 \\
\hline Standard deviation & & & & 2.189 & 0.000 \\
\hline $\begin{array}{l}\text { Water is safe for drinking only after } \\
\text { filtering }(1=\text { yes; } 0=\text { no })\end{array}$ & 0.08 & 0.468 & 0.000 & 1.234 & 0.000 \\
\hline Standard deviation & & & & 0.179 & 0.783 \\
\hline $\begin{array}{l}\text { Water is safe for drinking only after } \\
\text { boiling }(1=\text { yes; } 0=\text { no) }\end{array}$ & 0.23 & 0.396 & 0.000 & 0.921 & 0.000 \\
\hline Standard deviation & & & & 0.177 & 0.637 \\
\hline $\begin{array}{l}\text { Water is safe for drinking only after } \\
\text { filtering and boiling } \\
(1=\text { yes; } 0=\text { no })\end{array}$ & 0.08 & 0.246 & 0.037 & 0.385 & 0.066 \\
\hline Standard deviation & & & & 0.273 & 0.471 \\
\hline $\begin{array}{l}\text { Private tap dummy } \\
\qquad(1=\text { yes; } 0=\text { mini grid or standpost })\end{array}$ & 0.25 & 1.223 & 0.000 & 0.686 & 0.011 \\
\hline Standard deviation & & & & 4.142 & 0.000 \\
\hline $\begin{array}{l}\text { Mini-grid dummy } \\
\qquad(1=\text { yes; } 0 \text { = private tap or standpost })\end{array}$ & 0.25 & 1.058 & 0.000 & 1.218 & 0.000 \\
\hline Standard deviation & & & & 3.210 & 0.000 \\
\hline $\begin{array}{l}\text { Household chooses to opt out } \\
\qquad(1=\text { yes; } 0=\text { no })\end{array}$ & 0.25 & 2.005 & 0.000 & 3.484 & 0.000 \\
\hline Standard deviation & & & & 7.666 & 0.000 \\
\hline POOR*Proposed monthly water bill & 43 & -0.001 & 0.030 & & \\
\hline POOR*Volume of water per day & 90 & 0.00005 & 0.834 & & \\
\hline POOR*Hours of water supply per day & 2 & -0.0002 & 0.997 & & \\
\hline $\begin{array}{l}\text { POOR*Squared hours of water supply per } \\
\text { day }\end{array}$ & 32 & -0.0001 & 0.924 & & \\
\hline
\end{tabular}




\begin{tabular}{|c|c|c|c|c|c|}
\hline \multirow[b]{2}{*}{ Variable } & \multirow[b]{2}{*}{ Mean } & \multicolumn{2}{|c|}{ Conditional Logit } & \multicolumn{2}{|c|}{ Mixed Logit } \\
\hline & & Coefficient & p-value & Coefficient & p-value \\
\hline $\begin{array}{l}\text { POOR*Water is safe for drinking straight } \\
\text { from the tap }\end{array}$ & 0.04 & -0.019 & 0.915 & & \\
\hline $\begin{array}{l}\text { POOR*Water is safe for drinking only } \\
\text { after filtering }\end{array}$ & 0.02 & 0.272 & 0.322 & & \\
\hline $\begin{array}{l}\text { POOR*Water is safe for drinking only } \\
\text { after boiling }\end{array}$ & 0.04 & 0.128 & 0.408 & & \\
\hline $\begin{array}{l}\text { POOR*Water is safe for drinking only } \\
\text { after filtering and boiling }\end{array}$ & 0.02 & -0.107 & 0.636 & & \\
\hline POOR*Private tap dummy & 0.05 & -1.081 & 0.000 & & \\
\hline POOR*Mini-grid dummy & 0.05 & -0.581 & 0.000 & & \\
\hline POOR*Household chooses to opt out & 0.05 & -0.492 & 0.080 & & \\
\hline Number of Observations & & $21,616 *$ & & $21,616 *$ & \\
\hline Likelihood Ratio Statistic $\chi 2(11) / \chi 2(22)$ & & 2464 & 0.000 & - & \\
\hline Log likelihood & & -6260 & & $-0.830 \wedge$ & \\
\hline
\end{tabular}

* Approximately 1,800 households responded to 3 scenarios and 4 service levels, making the total sample equal 21,616.

$\wedge$ Indicates mean log likelihood. 